\title{
INCIDENCIA DE LA NUEVA POLÍTICA AGRARIA COMÚN EN LAS COMARCAS GRANADINAS DE BAZA Y HUÉSCAR
}

Abelardo VICO RUIZ *

\section{INTRODUCCIÓN}

El artículo pretende analizar la incidencia de la nueva Política Agraria Común sobre dos comarcas andaluzas cuya base es fundamentalmente agraria. En una primera parte se tratan de exponer los cuatro problemas fundamentales que atosigan hoy a la agricultura comunitaria: Degradación del medio ambiente, excedentes y carga presupuestaria, despoblamiento rural y malestar en el seno del GATT. Ha sido precisamente el anhelo de solucionar estos problemas el que ha dado origen a la reforma de la PAC. La reforma en sí cuenta con dos clases de medidas: Medidas estructurales y Medidas vía precios. Así, en los dos capítulos siguientes se analiza el posible impacto de estas medidas en el soporte agrario de las comarcas en cuestión. En resumen, a la postre se prevé un empobrecimiento de la renta agraria causado por el descenso de la protección vía precios, y una cierta recuperación de los ingresos si las medidas estructurales son adecuadamente implantadas. A pesar de todo, el estudio vaticina una zona demasiada subvencionada para el futuro, lo cual acarreará no pocos problemas sociales. La única solución probable pasaría por una búsqueda inmediata de alternativas a la actual situación y una reducción simultánea de las subvenciones si es que estas alternativas se encuentran.

Hasta ahora las sucesivas reformas de la Política Agraria Común no han tenido el efecto que sus creadores profetizaron. Una vez solucionado el primero y fundamental problema por el que surgió la misma: un abastecimiento suficiente de alimentos para los ciudadanos comunitarios, ha sido incapaz de aportar soluciones efectivas a las posteriores problemáticas que han ido surgiendo. A pesar 
de su necesaria imbricación, hoy podríamos separar dichas problemáticas en cuatro grandes grupos.

1. Degradación del medio ambiente. Determinadas prácticas agrarias causan un daño cierto a la envoltura ambiental en la que desarrollamos nuestra vida. Sumpsi (1990) ' las enumeró del siguiente modo:

- Deterioro de la calidad de las aguas provocado por un aumento de la presencia de nitratos, fosfatos, pesticidas, etc.

- Deterioro del suelo a causa de la desaparición de la cubierta vegetal y la erosión, el monocultivo y la acumulación de toxinas, la presencia de materiales pesados, la pérdida de riqueza en materia orgánica, el humus y la fauna microbiana.

- Deterioro del aire mediante emisiones de residuos y gases por la ganadería intensiva, industria agroalimentaria, etc.

- Deterioro del producto final (de la agricultura) como consecuencia de la pérdida de sus cualidades organolépticas ${ }^{2}$ en áreas de una mayor uniformidad, presencia de residuos de pesticidas y nitratos o de ciertos productos veterinarios y humanos. A ello se une un aumento de la sensibilidad de la planta a los ataques así como un incremento positivo de las especies inmunes a los tratamientos.

A los "deterioros" señalados por Sumpsi yo me atrevería a añadir uno más como es el deterioro de la diversidad faunística, la cual se ve sensiblemente mermada ante los ataques de la agricultura intensiva.

2. Excedentes y presupuesto comunitario. Siempre se ha dicho que para poder competir con garantías una región se debe especializar en aquellos productos para los que esté mejor dotada, tanto desde el punto de vista natural como de costes de producción. No obstante, en la CEE han existido demasiadas regiones que estaban bien dotadas para los mismos productos. Esta circunstancia, unida al ascenso progresivo y casi vertiginoso de los rendimientos y la productividad, gracias en gran parte a esas prácticas y elementos que dañan el medio ambiente, ha desembocado en unas tasas de autoabastecimiento muy superiores al $100 \%$ en los productos más importantes de la CEE, cereales, leche, came de vacuno, oleaginosas, azúcar... Si tenemos en cuenta que "entre 1973 y 1988 el volumen

1. GARCÍA AZCÁRATE, Tomás en Revista de Estudios Agro-Sociales nº 156, 1991/2, págs. 8788 citando a Sumpsi.

2. Cualidades que se perciben con los sentidos (untuosidad, aspereza, sabor, brillo, etc.) a diferencia de las cualidades químicas, microscópicas, etc. 
de producción agraria de la CEE aumentó anualmente en un $2 \%$ mientras que el consumo interno sólo creció un $0{ }^{\prime} 5 \%$ anual" "3, deduciremos que los excedentes han ido creciente año a año. Además, no existían perspectivas de verlos descender a corto plazo pues los hábitos de producción y consumo no se modificaban en nada.

Así, cuando los excedentes crecen de manera alarmante resulta lógico que el montante financiero destinado a subvencionarlos lo haga en la misma proporción. Concretamente, el presupuesto del FEOGA-Garantía ascendía a 4.500 millones de Ecus en 1975, se incrementó hasta 11.300 millones en 1980 y se disparó totalmente en la década de los ochenta hasta alcanzar los 31.500 millones en 1991 (el equivalente a 11.500 m. de Ecus en 1975) ${ }^{4}$. Además, el FEOGA Garantía nunca debería haber absorbido más del $75 \%$ del total del presupuesto agrícola según acuerdos institucionales, pero lo cierto es que en 1991 gastó el 93'7\% del mismo. Con ello se demuestra que el brutal incremento del presupuesto agrario no ha ido destinado a una modernización de las estructuras, sino a una subvención persistente de los precios, introduciendo al agricultor europeo en un mundo totalmente irreal y desconectado de las exigencias del mercado.

Pero esta política de precios no ha sido contraproducente sólo porque ha aislado al campesino del mercado, lo ha sido también porque ha estimulado la producción agravando con ello cada vez más el problema de los propios excedentes. El cultivador, sabedor de la existencia de un precio de intervención que le aseguraba unos ingresos mínimos, producía más para obtener más beneficios.

Por otra parte, desde un punto de vista puramente social nos interesa, además de la evolución del gasto total agrícola, el reparto que éste ha sufrido. En este sentido, la propia Comisión reconoce que la PAC vigente no ha contribuido a reducir las desigualdades sociales entre las clases de agricultores, pues según sus datos el $80 \%$ de las ayudas actuales se destinan al $20 \%$ de las explotaciones (DOC (COM) 100 f. pp. 2).

En consecuencia, un gasto agrícola tan desproporcionado no es sostenible desde la realidad económica actual y más cuando ni siquiera contribuye a aminorar las disparidades espaciales o a preparar estructuralmente al campo europeo para competir verdaderamente en el mercado internacional.

3. Despoblamiento rural. Aunque el éxodo rural ha descendido respecto a épocas pasadas, muchos habitantes de zonas rurales prefieren desplazar su resi-

3. Comisión Europea. "Documento de Reflexión de la Comisión sobre la evolución y futuro de la PAC"', pág. 2.

4. Comisión Europea. Op. cit. pág. 3. 
dencia a la ciudad ante la carencia de servicios -sobre todo sanitarios y educativos- y la falta de posibilidades laborales de sus descendientes. Si los trabajadores del campo abandonan sus lugares de origen, el problema no lo provoca la pérdida de su producción -más bien al contrario, hoy sería un beneficio- sino el riesgo de desertización de dichas zonas así como la pérdida de los valores culturales, paisajísticos y medioambientales que las caracterizan. Por lo tanto, y en este sentido, existen unos niveles de población por debajo de los cuales no debe caer una comarca, pues en caso contrario se perderían buena parte de los recursos naturales y humanos tan necesarios para la vida tanto de los propios como de los ajenos a dicha comarca.

4. Comercio internacional. La CEE mantiene continuas tensiones con las otras grandes potencias comerciales del mundo, sobre todo con EE.UU., a causa fundamentalmente de su comportamiento agrícola. A juicio de las mismas, las autoridades comunitarias protegen en exceso las producciones interiores distorsionando excesivamente el juego del libre mercado. Aunque otras potencias agrícolas como los propios Estados Unidos subvencionan a sus agricultores, no lo hacen de forma tan descarada. Así, la guerra comercial establecida en el seno del GATT por este motivo está perjudicando a todas las partes en conflicto. Y, de la misma manera, las partes "no firmarán la paz" mientras que la CEE no demuestre su voluntad de reducir significativamente su protección a los precios.

En atención a este estado de la cuestión, la CEE propone una reforma de su Política Agrícola Común para eliminar o al menos reducir los graves problemas expuestos. Las claves de la nueva PAC las ofreció la Comisión en dos documentos emitidos en Febrero y Julio de 1991 y mencionados en la bibliografía final. La reforma en sí consiste en una disminución en importancia de las ayudas vía precios y un aumento de la misma para la adaptación de las estructuras a los nuevos tiempos. Por lo tanto cabe hablar de unas medidas estructurales y de unas medidas destinadas a la modificación de los precios.

Como medidas estructurales se han concebido las siguientes actuaciones:

- Incentivar a los agricultores a utilizar prácticas de cultivo que respeten el medio ambiente.

- Remunerar su contribución a la conservación del espacio natural y el mantenimiento del tejido rural.

- Ayudar a la retirada de tierras del cultivo a largo plazo.

- Impulsar la reforestación.

- Mejorar el régimen de jubilación anticipada. 
En materia de precios prevee la reducción de la protección para determinadas Organizaciones Comunes de Mercado, posiblemente las más problemáticas y las que más excedentes exhiben. Esta reducción se llevará a cabo, bien disminuyendo el precio indicativo ${ }^{5}$, bien recortando el importe de las cuotas, introduciendo el sistema de cuotas en alguna Organización Común de Mercado que hasta ahora no esté regulada por él, o combinando más de un sistema de los propuestos.

Para compensar la pérdida de renta de los agricultores a causa de la caída de los precios, se establecerán unas ayudas a calcular, no ya según la producción, sino la superficie y los rendimientos medios de la zona donde se ubique la explotación.

Los productos afectados por la reforma serán: cereales, semillas oleaginosas, plantas proteaginosas, tabaco, leche, carne de vacuno y carne de ovino. Con los mismos se reúne el $75 \%$ de la producción agraria comunitaria sometida a OCM. Así, los principales sectores no afectados por la reforma en esta fase son el aceite de oliva, el azúcar, las frutas y hortalizas y el vino, ya que la Comisión opina "que no es oportuno volver a abrir el debate dado que recientemente han sido adoptadas decisiones relativas, por ejemplo, a la reforma global del régimen del aceite de oliva en 1990 y el régimen del azúcar en 1991" (COM (91) 258 f. pp. 30).

Con la aplicación de estas nuevas medidas la Comunidad confía en poder solucionar en alguna medida los problemas que le atosigan actualmente. En primer lugar desea contribuir desde el campo de la agricultura a la protección del medio ambiente, aunque esto suponga una división férrea entre lo que será agricultura capitalista y agricultura campesina. La primera tendrá permiso para utilizar fertilizantes, aumentar el riego, emplear plaguicidas, pesticidas, etc., en definitiva, continuar contaminando. A cambio, la agricultura campesina deberá renunciar por completo a esos hábitos perjudiciales para el entorno. En segundo lugar persigue una reducción de excedentes, por lo cual, la agricultura capitalista podrá seguir modernizándose y mecanizándose con el fin de incrementar sus rendimientos, pero la agricultura campesina deberá renunciar casi por completo a la producción. En tercer término no desea permitir que las sedes de la agricultura campesina se despueblen una vez que reduzcan las protecciones a los precios de sus productos vitales (cereales, ovino, bovino...). Para impedirlo concederán distintos tipos de ayudas a las rentas. Y por último desea contentar al GATT precisamente reduciendo sus protecciones vía precios, con lo que el mercado mundial se verá beneficiado, y aumentándolas vía estructuras, con lo que se evitará teóricamente el empobrecimiento de los agricultores europeos.

5. Con el precio indicativo desciende el precio de intervención y el precio umbral. 
Expuesto en sus rasgos principales el contenido de la nueva PAC, nos proponemos ahora dilucidar la incidencia que pueden tener las medidas enumeradas en la base agraria de dos comarcas andaluzas: Baza y Huéscar. Ambas colindan y se ubican en el cuadrante noreste de la provincia de Granada.

\section{INCIDENCIA DE LA REFORMA VÍA PRECIOS}

PORCENTAJE DE SUPERFICIE CULTIVADA EN BAZA-HUÉSCAR SEGÚN CULTIVO. \%

Cereales grano

\begin{tabular}{rr}
1982 & 1989 \\
\hline $85 ' 1$ & $73 ' 7$ \\
0'2 & 0'2 \\
0'1 & 0'2 \\
2'7 & 2'6 \\
1'6 & 1'3 \\
0'9 & 0 '6 \\
4'7 & 13 '3 \\
4'1 & $7 ' 2$ \\
0'2 & $0 ' 3$ \\
0'3 & $0 ' 2$
\end{tabular}

Fuente: Elaboración propia a partir de los datos de los Censos agrarios de 1982 y 1989. 


\section{REPARTO GANADERO EN BAZA-HUÉSCAR. $\%$ EN UNIDADES GANADERAS (UG)}

\begin{tabular}{|c|c|c|}
\hline & 1982 & 1989 \\
\hline 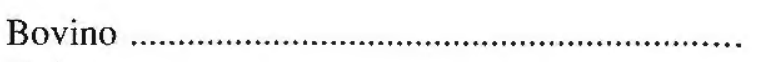 & 27 & $3 ’ 8$ \\
\hline Ovino & $633^{\prime} 8$ & $65^{\prime} 2$ \\
\hline 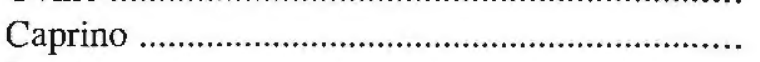 & $5 ’ 3$ & $8 ' 2$ \\
\hline 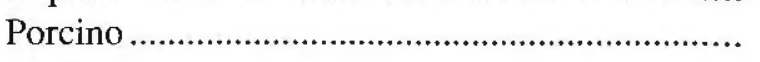 & $15^{\prime} 9$ & $13^{\prime} 7$ \\
\hline 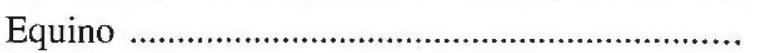 & $7 ' 6$ & $4 ’ 2$ \\
\hline 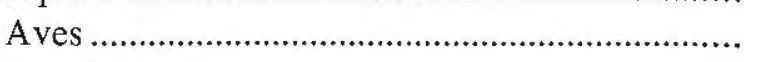 & $3 ’ 9$ & $4^{\prime} 5$ \\
\hline 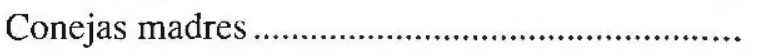 & $0 ’ 8$ & $0 ’ 3$ \\
\hline
\end{tabular}

Fuente: Elaboración propia a partir de los datos de los censos agrarios de 1982 y 1989.

Como hemos señalado en la introducción, los productos afectados por la reforma serán los cereales, las semillas oleaginosas, las plantas proteaginosas, el tabaco, la leche, la carne de vacuno y la carne de ovino. Sin duda, las comarcas de Baza y Huéscar se presentan como zonas anacrónicamente cerealísticas (Cuadro I). La Reforma tal y como la entiende la Comisión prevé el descenso de precios más brusco precisamente para el sector de los cereales, concretamente un $35 \%$ en tres campañas (desde los 155 Ecus/Tm actuales caerán hasta los 100 Ecus/Tm). Con ello, en un plazo de tres años desde la aplicación de la reforma, los agricultores de estas comarcas ingresarán por el capítulo de cereales $2 / 3$ de lo perciben actualmente. Es verdad que la Comunidad desea conceder unas ayudas directas a los propios agricultores para compensar la pérdida de renta causada por el descenso de los precios. No obstante, dichas ayudas directas se concederán en base a los rendimientos cerealísticos medios del área, y éstos son realmente muy bajos. Tengamos en cuenta que los rendimientos medios de la CEE en lo referente a cereales oscila entre los 4.000 y $5.000 \mathrm{~kg}$, mientras que los presentados por la provincia de Granada son mucho más bajos (Cuadro III). A mayor desventura de Huéscar y Baza su productividad cerealista media es bastante menor a la de ya de por sí exigua que ofrece la provincia granadina. Aunque no daremos cifras oficiales por la contradicción en la que caen las diferentes fuentes, sí diremos por ejemplo, que los rendimientos medios del trigo no superan muchos años los 1.000 kilogramos por hectárea. Ante estos rendimientos medios, cabe esperar 
unas ayudas directas cuyo importe no coinpense la disminución de ingresos generada por la caída de los precios.

\section{III}

\section{RENDIMIENTOS CEREALÍSTICOS MEDIOS DE LA PROVINCIA DE GRANADA. AÑO 1991}

Trigo

Cebada

Avena

Centeno

Triticale

Maíz
$2 ’ 359 \mathrm{Kg} / \mathrm{Ha}$

1 '385 Kg/Ha

$946 \mathrm{Kg} / \mathrm{Ha}$

$780 \mathrm{Kg} / \mathrm{Ha}$

$904 \mathrm{Kg} / \mathrm{Ha}$

7’348 Kg/Ha

Fuente: Delegación de Agricultura, Pesca y Alimentación de Granada.

Por otra parte, la presencia se semillas oleaginosas y plantas proteaginosas en las tierras bastetanas y oscenses es más bien pequeña, razón por la que la disminución de precios en estos productos afectará a un reducido número de agricultores. Ahora bien, el impacto sobre ellos será aún más duro si cabe que en el caso de los cereales, ya que el descenso del precio de intervención será similar al producido en el campo de los cereales, en con fin de evitar que estos cultivos se conviertan en una alternativa al trigo, la cebada, etc.; pero la disminución en sí se llevará a cabo sólo en una campaña y no en tres a causa de los compromisos adquiridos con el GATT. Ceteris paribus, las ayudas directas no serán tampoco excesivamente cuantiosas debido a los escasos rendimientos del área también en estos cultivos.

A los artículos analizados hasta ahora les espera un futuro difícil. Si consideramos que la mayoría de los agricultores de esta zona cultivan alguno de estos productos -sobre todo cereales-, a la mayoría de ellos se les avecina, por tanto, un futuro difícil. No obstante, la presencia de cereales, proteaginosas y oleaginosas ha ido descendiendo en los últimos años (Cuadro I), como si los campesinos hubieran sentido o adivinado las tendencias del mercado. Esta última afirmación quedará rubricada si observamos en el mismo Cuadro 1 los elementos que han visto aumentar su peso relativo en el reparto de los cultivos. Estos han sido fundamentalmente los frutales seguidos del olivar, dos artículos cuya de- 
manda ha crecido durante los últimos lustros en el Mercado Común; algo norma por otra parte, pues la tasa de autoabastecimiento de las frutas frescas y lo: aceites son del 85 y el $70 \%$ respectivamente en el seno comunitario. Responder c cómo los agricultores han ido abandonando poco a poco cultivos excedentarios рага adoptar otros deficitarios, no es tarea fácil, ya que la protección de los precios hacía casi tan rentables a los primeros como a los segundos. Quizás este cierto cambio de tendencia haya sido producto de la casualidad, o quizás existíar ventajas comparativas, a pėsar de todo, en los productos deficitarios como las frutas o los aceites. No resultaría acertado pensar que el incremento de frutales y olivos haya podido ser favorecido por un aumento de la superficie susceptible de riego en la zona de estudio, pues, según los datos de los dos últimos Censos Agrarios, la superficie regable ha descendido desde las 17.543 has hasta las 13.457. Este descenso, bastante considerable por cierto, ha sido experimentado en su totalidad por la comarca de Baza, y en su mayor parte por los términos municipales de Zújar y Freila, por la reciente construcción del Pantano de Negratín el cual sumergió grandes superficies de regadío.

La agricultura de la zona, con todas las deficiencias que aún conserva, ha pisado tímidamente el buen camino; pues, es una agricultura inadaptada adaptándose. Poco a poco abandona cultivos agotados comercialmente y aumenta sus potencialidades en aquellos más vendibles. Por ello, hoy, la reforma comunitaria vía precios le afectará, pero con menos intensidad de lo que hubiera hecho en 1982 por ejemplo, cuando la proporción de cereales suponía más del 85\% del total. Sin embargo no ha ocurrido igual con la ganadería. Con la cabaña ovina sucede en estas tierras algo similar a lo expuesto para los cereales, monopolizan por completo la producción. Sin embargo, no ha descendido ésta su peso específico como sí han hecho los cereales, sino que lo ha incrementado respecto al resto (Cuadro II). Los bovinos aunque mucho menos importantes, también han subido su número de cabezas. Con ello, el descenso de los precios para los derivados del ovino y del bovino afectará ahora a Baza y Huéscar más de lo que lo hubiera hecho hace una década. Para el caso de la ganadería las tendencias han sido las contrarias a las que marcaba el mercado. Es una ganadería inadaptada que aún no ha encontrado el buen camino. Quizás en esta ocasión sí ha sido la protección comunitaria de los precios la que ha impedido en gran parte el inicio de la readaptación. Sea como fuere, lo cierto es que las cuotas de la leche descenderán un $3 \%$ en tres campañas, los productos lácteos un $10 \%$, la carne de vacuno hasta un $15 \%$ en el mismo período, y el número de ovejas se verá sometido a unos contingentes rígidos (750 cabezas en la zona que nos ocupa). En este sentido, esta ganadería necesita cambiar con urgencia su rumbo comenzando a reducir el número de cabezas de animales que no ofrecen ninguna perspectiva de mercado 
en el futuro. Además, la esperanza de las ayudas directas no es tal en cuanto los rendimientos medios se encuentran también muy por debajo de los exhibidos por la mayor parte de las comarcas comunitarias.

En definitiva, la reducción de precios y de cuotas respectivamente en los dos productos principales del área -cereales y ovino- presagia una reducción de los ingresos familiares, que no será compensada con el importe de las ayudas directas a causa de los exiguos rendimientos exhibidos. De esta manera, la pérdida de poder adquisitivo respecto a los agricultores de otras zonas y con mayor intensidad respecto a los trabajadores de otros sectores económicos, parece más que probable.

Pero además, la nueva concepción de la política de precios comunitaria acarrea una serie de handicaps más para los trabajadores agrarios de estos lugares. Por un lado, el gobierno hará elaborar en un futuro inmediato un mapa de rendimientos, pues él será la base para el cálculo de las ayudas directas. Sin lugar a dudas la realización de estos mapas no será fácil, pues "unas comarcas rechazarán a sus vecinas, pero serán rechazadas a su vez por otras ligeramente más productivas, en un deseo legítimo de sostener rendimientos medios que dan derecho a primas mayores. En definitiva, las comarcas más desfavorecidas se quedarán aisladas, con rendimientos y primas ridículas..." ${ }^{6}$. Es casi seguro que la zona de Baza-Huéscar sufrirá esta marginación y se vea obligada a soportar ayudas ridículas, en consonancia con sus rendimientos. Por otro lado, hemos de tener en cuenta el agravio comparativo del que serán objeto las explotaciones más modernizadas, rentables y competitivas de estas comarcas.

Imaginemos una explotación bastetana que posea las mismas características en mecanización, fertilización, mano de obra, etc., que otra ubicada en las extensiones cerealísticas cordobesas o sevillanas. La explotación en cuestión podrá recibir unas ayudas directas mucho menores, sencillamente porque los rendimientos medios establecidos en Baza-Huéscar estarán muy por debajo de los vigentes en esas otras zonas de Sevilla o Córdoba donde se ubica su homóloga ?

En resumen, la incidencia de la reforma vía precios en Ia clase agraria local será bastante negativa en cuanto supondrá un descenso considerable de los ingresos de los agricultores, unos ingresos que no podrán ser recuperados en su totalidad por medio de las ayudas directas, pues al establecerse éstas según los rendimientos medios no serán excesivamente elevadas. Dicha reforma, al afectar de lleno a los dos productos principales de la zona: cereales y ovino, que suponen el

6. Esta idea fue expresada por TÍO SARALEGUI Carlos en "La Reforma de Ia PAC desde Ia perspectiva de las agriculturas del sur de la CEE" pág. 46.

7. Idea apuntada a un nivel general por Tío Saralegui, Carlos, Opus. cit, pág. 46. 
$73 \%$ de la agricultura y el $65 \%$ de la ganadería respectivamente, conllevará un generalización de los recortes financieros a la práctica totalidad de los trabajado res agrarios locales.

\section{INCIDENCIA DE LA REFORMA VÍA ESTRUCTURAS}

Trataremos de ofrecer seguidamente una panorámica de la situación estructu ral actual del campo en las tierras bastetanas y oscenses.

Existen una serie de hechos socioeconómicos que se han producido de form: manifiesta. En primer lugar, la población en edades jóvenes se sigue viendc obligada a emigrar temporal o definitivamente hacia núcleos fundamentalment turísticos, pues las posibilidades laborales de origen son muy restringidas. $\mathrm{Po}$ otra parte, aquellos emigrantes que partieron en los sesenta y setenta han regresa do tímidamente. Tanto los jóvenes emigrantes temporales que vuelven cada añc cuando la época turística finaliza, como esos otros que han retomado definitiva. mente ya en edad avanzada, se han acogido casi en su totalidad a una o a más de una de las protecciones sociales que ofrece el Estado: PER; subsidio normal de desempleo, ayuda familiar, etc.; ya que la escasa dinamicidad económica de la zona no permite reanudar una actividad laboral de una manera regular.

Estas situaciones pueden ser entendidas como causa o como consecuencia de] estado actual que presenta el campo de Baza y Huéscar, no obstante, dilucidar si son razón provocadora o efecto consecuente no es el objeto de este artículo, aunque no dejaría de ser interesante. Seguramente se trata de un proceso imbricado donde estas ayudas aparecen como causa y consecuencia a la vez. Sólo pretendemos en este momento constatar una situación estructural que aparece estrechamente relacionada con los fenómenos expuestos anteriormente, una situación de abandono, descuido e indiferencia crecientes hacia la tierra.

El cuadrante noreste de la provincia de Granada ha ido perdiendo población, la mayor parte de ella en edades jóvenes, cuando ésta no ha sido la tendencia habitual ni de Granada ni de Andalucía globalmente (Cuadro IV). Ante las escasas perspectivas que ofrecía la agricultura en la década pasada, han sido agricultores o potenciales agricultores jóvenes los que han abandonado en mayor cuantía sus lugares de origen, elevando significativamente con ello la edad media de la población agraria en estas comarcas. El porcentaje de agricultores mayores de 55 años en las comarcas de Baza y Huéscar es del 51'6\%, una cantidad superior a la provincial o a la regional. Además, el proceso de envejecimiento ha sido vertiginoso ya que hace tan sólo una década estas comarcas presentaban unos trabajadores agrarios bastante más jóvenes que los existentes en Granada o en 
Andalucía (Cuadro V). En definitiva, la zona objeto de análisis está padeciendo un proceso agudo de despoblamiento al que se une una tendencia especial al envejecimiento demográfico.

\section{CUADRO IV}

INCREMENTOS DE LA POBLACIÓN DE HECHO. \%.

$1981-86 \quad 1986-91 \quad 1981-91$

Baza-Huéscar

$\begin{array}{rrr}-3 ' 8 & -9{ }^{\prime} 1 & -12^{\prime} 5 \\ 4{ }^{\prime} 6 & 1 ' 2 & 5^{\prime} 9 \\ 22^{\prime} 2 & -11^{\prime} 5 & 8 ' 1\end{array}$

Granada

$22 ' 2-11 ' 5$

8'1

Andalucía

Fuente: Elaboración propia a partir de los datos del Censo de 1981, el Padrón de 1986 y el Avance de Resultados del Censo de 1991.

\section{CUADRO V}

\section{PORCENTAJE DE EMPRESARIOS AGRARIOS MAYORES DE 55 AÑOS}

\begin{tabular}{|c|c|c|c|}
\hline & 1972 & 1982 & 1989 \\
\hline 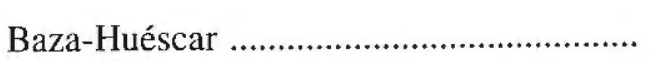 & $41 ’ 4$ & $39^{\prime} 9$ & $51^{\prime} 6$ \\
\hline 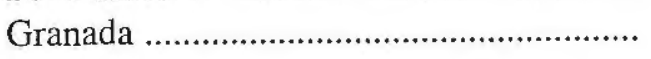 & $44^{\prime} 4$ & $41^{\prime} 9$ & $51^{\prime} 2$ \\
\hline Andalucía & $47^{\prime} 8$ & $44^{\prime} 1$ & $49^{\prime} 6$ \\
\hline
\end{tabular}

Fuente: Elaboración propia a partir de los Censos agrarios correspondientes.

La juventud de los agricultores se ha ido difuminando, y con ella quizás se haya perdido buena parte de la capacidad de innovación que les pudo animar un día. Así, no ha existido en los últimos años ningún interés por aumentar el nivel de mecanización y tecnificación del campo, en contraposición al total de agricultores granadinos los cuales sí han incrementado notablemente el número de tractores que trabajan sus tierras ${ }^{*}$. No se puede pensar que la desventaja comparativa del territorio BazaHuéscar en cuanto a mecanización obedece a razones naturales. La fisonomía del

8. Hemos considerado el tractor como el elemento más representativo de la mecanización, aunque identificar totalmente tractorización y mecanización, sería, reconozcámoslo, una sinécdoque un tanto licenciosa. 
terreno no es más abrupta en estas comarcas norteñas que en la mayor parte de territorio provincial granadino, más bien al contrario. Han de existir otras causas par: explicar la menor presencia relativa de tractores en ellas. Por ejemplo, el aumento di explotaciones pequeñas y el incremento de la parcelación han hecho que la adquisi ción de maquinaria haya resultado menos rentable y más difícil. Además, el regress temporal de bastantes ayudas familiares, ocupados en el peńodo estival en trabajo: hosteleros, no ha hecho tan necesaria la compra de maquinaria para trabajar la: explotaciones pequeñas -que constituyen la mayoría-. El titular de la explotación y estas ayudas familiares -la mayoría de ellas temporales, pero algunas también perma nentes, sobre todo colegiales- realizan perfectamente el trabajo de explotación, J cuando esporádicamente han sido necesarios servicios mecanizados, éstos han sidc alquilados. La inferior mecanización relativa de la zona de estudio se puede aprecias en el Cuadro VI.

Al margen de la mecanización existen otros factores que ayudan a entender e. atraso comparativo de este área. El apego a las raíces culturales ha podido sobre cualquier intento de aumentar el tamaño medio de las explotaciones y convertirlas así en unidades más rentables. El número de explotaciones entre 0 y 5 Hectáreas. lejos de descender se ha incrementado** (Cuadro VII). Ahora bien, ¿cuál ha sido la causa de este sensible aumento de la atomización? Alguna bibliografía ha aportado un argumento general con el cual pretenden explicar, si no todo, al menos sí buena parte del fenómeno: En la década de los ochenta se ha producido un retorno considerable de emigrantes (emigración de retomo), tal que buena parte de ellos han adquirido pequeñas explotaciones en las que practicar una marginal agricultura a tiempo parcial. Ha sido esta nueva adquisición de explotaciones pequeñas la responsable, en buena parte, del aumento de las empresas entre 0 y 5 Has. He tratado de comprobar si este proceso ha sido cierto para las comarcas que nos ocupan. Para ello hemos escogido un municipio testigo, el municipio de Freila. Realizado el estudio, de todos los varones ${ }^{* * *}$ entre 18 y 55 años que han Ilegado a la localidad entre 1982 y 1991 , solamente el 9\% han adquirido tierras; es decir, 4 de los 47 nuevos empadronados. Además, en casi ningún caso han accedido a explotaciones pequeñas, sino a explotaciones superiores a 5 Has. A falta de extender este estudio a los restantes municipios de sendas comarcas -hecho que se realizará en trabajos posteriores-, sí podemos

** Este incremento no se ha debido a la fragmentación de las propias explotaciones entre 0 y 5 Has, sino a la división de otras mayores; ya que, el número de Has. incluido en explotaciones desde 0 a 5 Has. ha ascendido de 11.172 en 1982 a 11.495 en 1989. Si el incremento se hubiese producido por la fragmentación de las propias explotaciones entre 0 y 5 Has. esta cifra no hubiese ascendido.

*** Se ha considerado exclusivamente la inmigración maseulina porque la adquisición de tierras por parte de féminas en estas zonas es prácticamente nula. De haber considerado también a las mujeres, sólo hubiésemos logrado desvirtuar el dato porcentual. 
adelantar que, probablemente, el crecimiento de las explotaciones pequeñas se debe en una proporción muy pequeña al retomo de emigrantes o a la llegada de personas nuevas al pueblo. Las principales causas quizás deban ser buscadas en divisiones procedentes de herencia o en puras transferencias de tierra entre los propios vecinos, las cuales obedecerán a distintos motivos. En todo caso, el retorno de emigrantes aparece como una causa explicativa menor -al menos por ahora y a falta de extender el ámbito geográfico de estudiode la reciente atomización del campo en esta zona. Aunque, debida a la razón que fuere, lo cierto es que la creciente atomización de la explotación de estas tierras es un hecho constatable que va en contra de su modemización.

Por último, otro factor que delata la falta de modemización se identifica con la parcelación de las explotaciones (Cuadro VIII). Esta ha aumentado de manera muy significativa en el último período intercensal, obstaculizando con ello cualquier proceso de mecanización y aumentando el tiempo perdido en los desplazamientos de parcela a parcela.

\section{CUADRO VI}

\section{MECANIZACIÓN DE LAS COMARCAS DE BAZA Y HUÉSCAR EN COMPARACIÓN A LA MECANIZACIÓN DE GRANADA EN SU CONJUNTO}

Número de tractores

\begin{tabular}{rcrrr}
\hline & \multicolumn{2}{c}{ Baza Huéscar } & \multicolumn{2}{c}{ Granada prov. } \\
CV & 1988 & 1991 & 1988 & 1991 \\
\hline 34 & 349 & 353 & 892 & 966 \\
$35-54$ & 393 & 354 & 2092 & 2124 \\
$55-79$ & 733 & 737 & 3333 & 3437 \\
$80-108$ & 267 & 190 & 958 & 992 \\
108 & 100 & 138 & 213 & 372
\end{tabular}

CV/ 100 Has. labradas

\begin{tabular}{lrr}
\hline & 1988 & 1991 \\
\hline Baza-H. & $79^{\prime} 4$ & $77^{\prime} 3$ \\
Granada & $91^{\prime} 0$ & $83^{\prime} 4$ \\
& & \\
& &
\end{tabular}

Fuente: Elaboración propia a partir de datos facilitados por la Delegación Provincial de Agricultura, Pesca y Alimentación de Granada.

EI número de CV se ha obtenido multiplicando la cantidad de tractores situados en cada intervalo por la cantidad media del mismo; esto es, si entre $3554 \mathrm{CV}$ existen 393 tractores, multiplicamos esa cantidad por la media de intervalo, $35+54 / 2=45$. Así se han obtenido las cantidades totales de CV que poseían tanto Baza-Huéscar como su provincia. Observaremos que el intervalo menor y el mayor no poseen los dos límites sino uno sólo; así, se ha considerado límite inferior del intervalo $34 \mathrm{CV}$ la cantidad de $25 \mathrm{CV}$, y límite superior del intervalo 108 la cantidad de $180 \mathrm{CV}$, pues se considera que apenas se fabrican tractores por dehajo y por encima de esas potencias.

La cantidad de hectáreas base para hallar el número de CV por cada 100 Has. ha sido la de 1989 para los dos años, al no poder poseer otra. 


\section{CUADRO VII}

\section{NÚMERO DE EXPLOTACIONES EN BAZA-HUÉSCAR}

\begin{tabular}{|c|c|c|c|}
\hline & 1972 & 1982 & 1989 \\
\hline 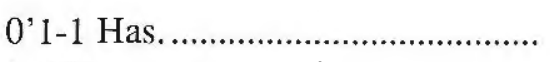 & 3396 & 2675 & 2939 \\
\hline 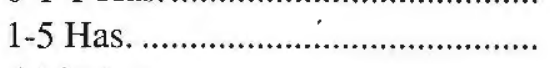 & 4549 & 4001 & 4118 \\
\hline 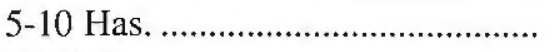 & 2161 & 1629 & 1541 \\
\hline 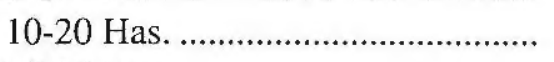 & 1635 & 1273 & 997 \\
\hline 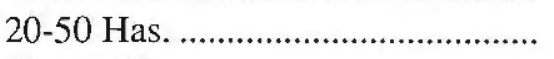 & 1141 & 1012 & 778 \\
\hline 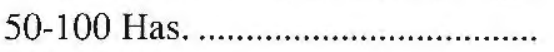 & 489 & 488 & 445 \\
\hline 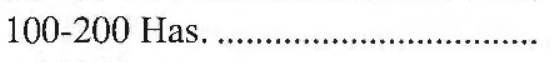 & 231 & 311 & 288 \\
\hline 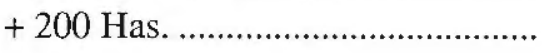 & 397 & 263 & 248 \\
\hline
\end{tabular}

Fuente: Elaboración propia a partir de los datos de los Censos Agrarios de los años señalados.

\section{CUADRO VIII}

\section{NÚMERO DE PARCELAS POR EXPLOTACIÓN}

\begin{tabular}{|c|c|c|}
\hline & 1982 & 1989 \\
\hline 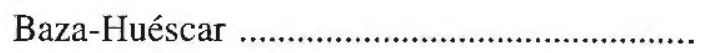 & 377 & $4^{\prime} 4$ \\
\hline 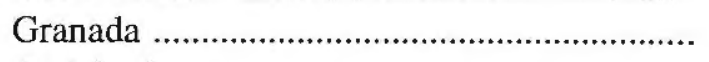 & $3^{\prime} 0$ & $3 ’ 2$ \\
\hline 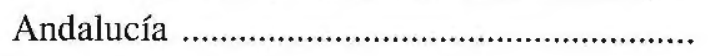 & $2 ' 8$ & $2^{\prime} 9$ \\
\hline
\end{tabular}

Fuente: Elaboración propia a partir de los Censos Agrarios correspondientes.

En parámetros cualitativos los descensos de actividad agraria han sido notables. La intensidad del trabajo que han recibido las explotaciones bastetatas y oscenses ha caído más de un $20 \%$ entre 1982 y 1989, cantidad que sorprende por su importancia en comparación a la que han experimentado su provincia y región de marco (Cuadro IX). De igual manera, el porcentaje de tierras labradas llegó a ser bastante superior al existente en Granada o Andalucía alrededor de 1972 e incluso 1982, sin embargo en 1989 ya se ha colocado al nivel de estos dos puntos contextuales al sufrir un descenso muy considerable en la década de los ochenta 
(Cuadro X). Además, entre estas tierras labradas son cada vez menos las que se siembran, pues el peso del barbecho ha ascendido desde el-33'2\% hasta el $37^{\prime} 5 \%$ en los siete años que separan los dos últimos censos agrarios.

\section{CUADRO IX}

\section{TRABAJO TOTAL EN LA EXPLOTACIÓN EN UNIDADES DE TRABAJO AL AÑO (UTA)}

\begin{tabular}{|c|c|c|c|}
\hline & 1982 & Increm. & 1989 \\
\hline 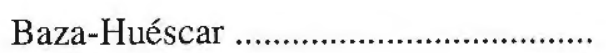 & 3890 & $-20^{\prime} 1 \%$ & 3107 \\
\hline 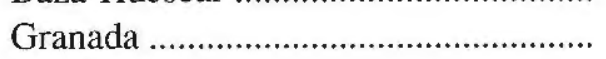 & 30762 & $-11 ' 3 \%$ & 27282 \\
\hline 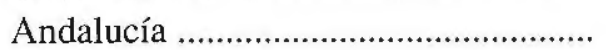 & 251634 & $-0^{\prime} 6 \%$ & 250137 \\
\hline
\end{tabular}

Fuente: Elaboración propia a partir de los Censos Agrarios correspondientes.

\section{CUADRO X}

\section{PORCENTAJE DE TIERRAS LABRADAS RESPECTO AL TOTAL DE TIERRAS INCLUIDAS EN EXPLOTACIONES AGRAR1AS}

\begin{tabular}{|c|c|c|c|}
\hline & 1972 & 1982 & 1989 \\
\hline 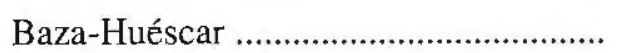 & $54^{\prime} 2$ & $48^{\prime} 7$ & $45^{\prime} 1$ \\
\hline 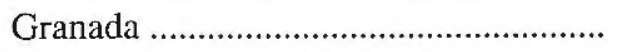 & $50^{\prime} 0$ & $48^{\prime} 4$ & $44^{\prime} 9$ \\
\hline 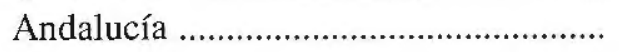 & $47^{\prime} 7$ & $44^{\prime} 9$ & $44^{\prime} 6$ \\
\hline
\end{tabular}

Fuente: Elaboración propia a partir de los Censos Agrarios correspondientes.

Por todo ello, se puede hablar de estancamiento en el proceso de modemización de las explotaciones y de caída notable de la actividad agraria. Ambos hechos se han producido de una manera mucho más drástico en estas comarcas que en sus puntos de referencia más cercanos -la provincia de Granada y Andalucía-, de ahí su especial significación.

La tierra está siendo paulatinamente abandonada y por lo tanto produce menos ingresos para las familias agrarias. Por este motivo, el Estado ha de establecer una serie de prestaciones sociales que complementen sus rentas: PER, subsidio 
normal de desempleo, ayuda familiar... En muchas ocasiones, es verdad, los campesinos se ven obligados a dejar la tierra porque ésta de alguna manera les traiciona; después de castigarse jornada a jornada con las duras faenas del campo ven crecer una cosecha exigua y raquítica. El Estado ha de ayudar sin duda a aquéllos que manifiestan y repetidamente han demostrado que no pueden vivir de la tierra. Ahora bien, en otros casos existen trabajadores agrarios que insolidariamente abusan del sistema, pues solicitan y reciben una ayuda estatal cuando de hecho pueden vivir de la tierra o de alguna actividad colateral. Abandonan su explotación -al menos parcialmente-, porque se les concede la ayuda del Plan de Empleo Rural o el subsidio de desempleo y consiguen un ingreso seguro sin necesidad de tomar preocupaciones. En estos últimos casos, las prestaciones sociales estatales se han convertido en causa del abandono de la tierra y no en consecuencia.

Podríamos pensar que los montantes económicos del subsidio por desempleo o el PER son tan exiguos que no son un estímulo suficiente como para abandonar el campo. No es cierto, en una zona donde los rendimientos del campo son generalmente bajos y el coste de la vida no es demasiado elevado, sí lo son.

Por otra parte, existen una serie de medidas estructurales como el cese anticipado de la actividad agraria o la retirada de tierras de cultivos herbáceos, que han sido aplicadas durante los últimos años.

La verdad es que el éxito de estas medidas ha sido escaso en estas comarcas y en general en todo el país, no obstante han contribuido en algo al abandono de la tierra. En cierta manera han actuado como otro pequeño incentivo para el divorcio entre el agricultor y la tierra.

Por lo tanto, los estímulos más o menos concienzudos de las instituciones han promovido hasta ahora un importante abandono de la actividad agraria en la zona tratada. Los estímulos que ofrecerá ahora la CEE por medio del Estado español, provocarán un mayor abandono, aunque éste será muy sui generis, se tratará de un abandono del cultivo pero no del cuidado de la tierra. Hemos de considerar que, si los débiles estímulos que ha organizado hasta ahora el poder -prestaciones sociales y medidas estructurales- han provocado un abandono cierto del cultivo, los estímulos que tiene preparados la Comunidad, al ser mucho más importantes, provocarán, si son adecuadamente desarrollados, un abandono mucho más elevado del propio cultivo. Las primas económicas por no cultivar serán ahora mucho más cuantiosas, de ahí que se prevea un mayor número de campesinos que renuncien al cultivo.

Vistas las medidas estructurales que adoptará la nueva PAC, y vista la estructura del campo en las comarcas de Baza y Huéscar, nos atrevemos a proponer un Decálogo que recoja los posibles efectos concretos que provocarán las medidas estructurales de la nueva PAC en el paisaje agrario del área de estudio. 


\section{DECÁLOGO}

1. Asistiremos a una reducción sensible del empleo de fertilizantes, aunque su utilización en las explotaciones de esta zona no es muy intensiva; así como a una estabilización o descenso de la mecanización, sobre todo aquélla dedicada exclusivamente a cereales.

2. Una leve introducción de la agricultura biológica, ya que este tipo de agricultura es totalmente desconocida en estos parajes. Por su respeto al medio ambiente será especialmente primada desde las instituciones comunitarias. Las técnicas tradicionales que exige la agricultura biológica como la rotación de cultivos o la integración de agricultura y ganadería, aún siguen perviviendo en la mayor parte de los núcleos rurales del área; por lo cual, sólo se necesitaría un leve estímulo para incorporar técnicas modernas y complementarias de éstas: semillas mejoradas, lucha contra plagas, etc. Es ésta una agricultura que puede aportar verdaderas salidas económicas a la zona, pues estudios en Francia y Alemania han demostrado que el $30 \%$ de los consumidores están dispuestos a pagar entre un 20 y $30 \%$ más caros los productos biológicos. Además, Reganold et alt (1990) señalan como "los menores costes de producción de la agricultura biológica compensan en muchos casos los menores rendimientos, de tal manera que el beneficio de los agricultores biológicos es a menudo igual o superior al de los agricultores clásicos". Sin embargo, la agricultura biológica no puede convertirse en la salvadora económica de la zona, ya que su desarrollo potencial es muy limitado debido a que un aumento descontrolado de la oferta haría bajar los precios y desaparecería el sobreprecio pagado respecto al producto tradicional ${ }^{9}$.

3. Una extensificación aún más acusada de las explotaciones, de forma que el porcentaje de tierras labradas continuará descendiendo, algo similar ocurrirá con las tierras sembradas, mientras que por el contrario aumentan los pastizales.

4. Un descenso significativo del número de bovinos y ovinos, sobre todo de estos últimos, a la vez que asistiremos a un desarrollo especial de la oveja segureña. Ese desarrollo especial será extensible a cualquier pieza ganadera de raza local.

5. La adopción de ciertas técnicas de cultivo nuevas y respetuosas con el medio ambiente, las cuales son desconocidas hasta ahora.

6. Un sensible rejuvenecimiento de la población agraria, la cual revitalizará en cierta medida la estructura de edades y garantizará un menor despoblamiento.

9. GARCÍA AZCÁRATE, Tomás en “¿Se ha agotado la Revolución verde?”, Revista de Estudios Agro-Sociales, nº 156, 1991/2, pág. 96. Aquí presenta este autor las ideas que han servido de base para la reflexión, así como las citas textuales de los autores en cuestión. 
Este es uno de los puntos más delicados y frágiles. Por ello su éxito está más condicionado que cualquier otro a una verdadera seriedad política y económica en la aplicación de las medidas. Conseguir un rejuvenecimiento, aún leve, en estructuras demográficas tan viciadas como las de estas zonas, es tarea nada fácil.

7. Una dedicación preferente hacia fines no agrarios de las tierras dejadas por los jubilados anticipados.

8. Un aumento de los parajes destinados al ocio y el esparcimiento público (merenderos, miradores, lugares típicos, etc.).

9. Un incremento cierto del potencial forestal de la zona.

10. La adopción de especies que soporten las duras condiciones climáticas y edáficas para llevar a cabo dicha repoblación, particularmente algunas coníferas.

Como se puede apreciar, la política de estructuras provocará un receso de la agricultura y ganadería tradicionales, estimulará nuevas formas de agricultura respetuosas con el medio ambiente -agricultura biológica-, incorporará técnicas novedosas no contaminantes, rejuvenecerá la población agraria y contribuirá a incrementar el manto forestal de estas tierras. Todo ello en teoría, pues el grado de alcance de estas repercusiones, o dicho de otra manera sus posibilidades de éxito, dependerán de dos factores esencialmente. En primer lugar de la campaña de educación que organice el poder público para instigar la aplicación de las nuevas normas. Apreciemos que decimos campaña de educación y no campaña de información, pues en la mayoría de los casos es preciso un proceso más complejo y más completo que el de la propia información. El dar a conocer la posibilidad de retirar algunas hectáreas de la producción a cambio de algunos ecus al año, por ejemplo, sólo precisa del hecho puntual de la información; pero el introducir en el campo nuevas técnicas de cultivo respetuosas con el medio ambiente, cuidar explotaciones forestales, o producir productos biológicos, exige todo un largo programa educativo. Cabría decir: Información sí, más no sólo información. Información en el marco de un plan general de formación. Sólo así se podrá realizar un seguimiento de la implantación de los nuevos hábitos y formas de hacer agricultura. Y en segundo lugar, el éxito dependerá de las primas económicas que reciban los agricultores por aplicar en sus propiedades las directrices dictadas.

Del primero de estos factores citados aún no conocemos nada, sin embargo del segundo ya sabemos las subvenciones máximas fijadas por el Consejo Comunitario para primar algunas actuaciones. Presentaremos algunas de estas subvenciones tratando de recoger todas aquéllas que puedan tener alguna acogida en las comarcas de estudio:

- 84.000 pts. por Ha. y año por la retirada de tierras.

- 56.000 pts. por Ha. y año por la retirada de olivar especializado. 
- 35.000 pts. por Ha. y año por cada unidad ganadera de ovino o bovino que se reduzca.

- Para los agricultores que se acojan a la jubilación anticipada 560.000 pts. por explotación más una prima anual de 35.000 pts. por Ha. sin que la dotación global pueda sobrepasar 1.400 .000 pts. anuales.

- 280.000 pts. por plantar eucaliptos más unas ayudas anuales durante cinco años.

- 420.000 pts. Ha. para las plantaciones de coníferas, 35.000 pts. para gastos de mantenimiento durante los dos primeros años y 21.000 para los años siguientes.

- 560.000 pts. por Ha. para la puesta de frondosas o para las plantaciones que contengan como mínimo un $75 \%$ de frondosas, 70.000 pts. anuales para gastos de mantenimiento durante los dos primeros años y 42.000 pts. en los años siguientes.

Aquí hemos expuesto algunas de las referencias legisladas por la Comunidad, pero no debemos olvidar que éstas son cantidades máximas. Ahora serán los gobiernos nacionales los que deberán designar las cantidades exactas a aplicar en cada país en los programas que desarrollarán antes de mediados 1993. Estas cantidades serán muy bien pensadas por cada gobierno pues éste tendrá que financiar un tanto por ciento, variable según las zonas, de las mismas. Si fija unas primas muy altas, el propio gobierno deberá corresponder con un desembolso muy elevado para cubrir su tanto por ciento.

El tanto por ciento restante lo cofinancia la CEE. Cabe suponer que los países con economías más poderosas fijen ayudas más importantes, pues las podrán cofinanciar, mientras que aquéllos con economías más débiles como España no puedan permitirse más que cantidades modestas. Baza y Huéscar aparecen como zonas incluidas en el Objetivo 1 de la Directiva 797/85, lo cual quiere decir que el gobierno español sólo tendrá que financiar el $25 \%$ de las ayudas destinadas a sus trabajadores agrarios, cuando lo normal es un porcentaje de cofinanciación del $50 \%$. Aún con esta facilidad, el Estado español fijará ayudas exiguas mientas que holandeses, alemanes, belgas, daneses, etc. , establecen ayudas que prácticamente igualan los topes máximos fijados por la Comunidad y presentados anteriormente. Hasta ahora tiene establecida una prima por cabeza de vacuno de 29 ecus, mientras que en los Países Bajos superaba los 70. Es un claro ejemplo de una situación que ahora se repetirá y pervivirá.

Hemos de admitir que las ayudas que fijará nuestro país serán inferiores a las de la mayoría de sus socios comunitarios. Sin embargo, aún siendo más pequeñas, el estímulo que supondrán para el cese de actividad y la retirada de tierras 
del cultivo será mucho mayor que el experimentado hasta ahora. Las ayudas qu fijará el gobierno, con ser precarias a nivel general, serán aceptadas a cambio de cese de actividad en unas zonas con unos precios bajos y unos niveles di autosubsistencia elevados. Es decir, serán lo suficientemente importantes comı para "ir tirando" siempre que no existan sorpresas y el gobierno fije unas ayuda auténticamente ridículas.

En este sentido, si las dotaciones económicas serán escasas pero suficientes salvo ingratas sorpresas-, sólo resta esperar la puesta en marcha de una campañi de formación adecuada que demuestre a los agricultores la conveniencia de lo cambios en sus explotaciones. Con la combinación de ambas componentes st puede garantizar un cierto éxito de la nueva política de estructuras comunitaria eı las comarcas de Baza y Huéscar.

Así, cuando la nueva política de precios va a constituir un descenso seguro d las rentas de los agricultores, la política de estructuras venidera supone uni esperanza para la reorientación ecológica de las explotaciones conservando uno: ingresos aceptables, sobre todo considerando el menor coste de la vida en esto: núcleos.

Ahora bien, la política de estructuras tal y como está concebida conserva ur peligro cierto. Nuestra sociedad, o algunos sectores de ella, pueden creer que lá subvención de los agricultores de ésta y otras zonas similares es una soluciór definitiva, pues con ella muchos intereses económicos, sociales y hasta electorales se muestran satisfechos. Sin embargo, nadie puede aceptar bajo la excusa $d \epsilon$ la solidaridad social -otra cosa es que desee aceptarlo porque forma parte $\mathrm{d} \epsilon$ alguno de los intereses antedichos-, nadie puede aceptar bajo esa excusa, decimos, la renuncia total a encontrar alternativas que permitan disminuir las ayudas a estos agricultores. En ningún momento nadie tiene autoridad social para creat enclaves rurales perennemente subvencionados. Por una parte, los activos de los próximos años soportarán sobre sus espaldas las crecientes subvenciones concedidas a los "pasivos agrarios" 10 de estas zonas. Pero no pensemos que el hecho resulta menos dañino para los propios trabajadores agrarios, los cuales, sabiéndose asegurados de un cheque mensual o anual, y con demasiado tiempo libre, descuidan tradiciones y potencian vicios como el alcoholismo. Este proceso de degradación en cuanto a los valores y los comportamientos se vislumbra ya en algunos puntos de las comarcas tratadas como consecuencia, en gran medida, de la concesiones económicas gratuitas ofrecidas por el Plan de Empleo Rural, el subsidio de desempleo, la ayuda familiar, etc. La solución no sería, obviamente, 
eliminar estas prestaciones sociales, sino mantenerlas como un recurso temporal mientras paralelamente se estimulan alternativas económicas de futuro. Estas ayudas son necesarias de una manera coyuntural, pero desde luego no son el sustituto sine die del trabajo. En ningún momento pueden constituir la justificación para dejar de buscar nuevas formas de desarrollo económico para ésta y otras zonas similares, si es que la agricultura y la ganadería tradicionales han de remitir forzosamente.

\section{CONCLUSIONES}

Es por ello que, con la propia iniciativa de los trabajadores rurales y la ayuda de las instituciones se debe aguijonear lo que la OCDE ha llamado Desarrollo Empresarial Endógeno, un desarrollo basado en el aprovechamiento de los recursos naturales infrautilizados e infravalorados. Este puede ser alcanzable hoy,

$1^{\circ}$ Potenciando la implantación de cultivos destinados a fines no alimentarios -madera, plantas olorosas...-, los cuales sí serán vendibles en el futuro mercado común.

$2^{\text {Q }}$ Procurando el desarrollo de otros sectores económicos alternativos a la agricultura-ganadería tradicionales (caza, pesca fluvial, otros deportes, turismo rural, artesanía típica del lugar...).

3ํ Estimular otras formas de agricultura -agricultura biológica- y ganadería cría de razas locales-.

Baza y Huéscar deben cambiar sus orientaciones ancestrales al menos en parte, sin embargo esto no quiere decir que no puedan desarrollar otras con un futuro abierto. La nueva PAC desea crear en comarcas como éstas reductos donde los trabajadores agrarios no produzcan sino que se dediquen a conservar la naturaleza y proteger el medio ambiente a cambio de una subvención. Esta situación sólo es aceptable si:

a) Esa subvención económica es lo suficientemente importante para vivir. Si el mundo urbano y los grandes agricultores desean permitirse el "lujo" de tener cuidadores permanentes de sus refugios vacacionales, han de pagarlos adecuadamente.

b) Si se buscan simultáneamente alternativas económicas que permitan un día reducir dicha subvención e incluso eliminarla, al menos para parte de los trabajadores agrarios. 
Parece que Baza y Huéscar habrán de renunciar por el momento a la aspiración de conseguir una agricultura capitalista y moderna, una agricultura que por otra parte aún les quedaba muy lejos, para perpetuar la agricultura campesina convirtiéndola ahora en más ecológica que nunca. Será una agricultura "sustentadora del equilibrio social, territorial y ecológico y, en la medida que cumple funciones sociales y de beneficio colectivo, (...) una actividad subsidiada" ${ }^{11}$.

La nueva PAC es una puerta a la esperanza, una posibilidad real de mejorar la existencia de los trabajadores agrarios en ésta y otras zonas empobrecidas. Esperemos que no suponga, como casi siempre, un nuevo instrumento para aumentar las desigualdades entre las áreas débiles y las poderosas. Ojalá que algunos investigadores se equivoquen cuando anuncian que esta nueva PAC ha comprometido toda la estrategia de futuro del mundo rural al convertir a la agricultura en un sector aún más subsidiado ${ }^{12}$. Yo en el fondo sé que esto es muy posible, sé que la cornada al mundo agrario, y más en zonas como Baza y Huéscar, es profunda y con varias trayectorias; no obstante, como pseudoagricultor no puede perder la esperanza de que las cosas mejoren con la nueva PAC.

\section{ANEXO}

A lo largo del artículo hemos señalado dos como las condiciones imprescindibles para la consecusión de un éxito adecuado en la aplicación de las medidas: a) Una campaña de formación que haga llegar las nuevas posibilidades a los agricultores, y b) Unas dotaciones económicas suficientes. Quizás convendría añadir una más a raíz de las últimas experiencias que se han vivido con la aplicación de algunas medidas estructurales. Esta sería, c) Una flexibilidad por parte del gobierno en la exigencia de documentos.

De todos es conocido que los agricultores conforman un mundo aparte. Como tal debe ser tratado, no con privilegio, sino con diferencia. No se les puede exigir obligatoriamente documentos como facturas, seguros o contratos de arrendamiento, y menos aún de largos períodos, pues en tal caso muy pocos dispondrán de ellos y se podrán acoger a las medidas legisladas. La actual experiencia de las medidas estructurales debe servir de escarmiento. Hoy, para llevar a cabo una retirada de cultivos herbáceos -una de las medidas estructurales en vigor- se requieren los siguientes documentos:

11. CRUZ VILLALÓN, Josefina, "El futuro de las agriculturas del sur de Europa", págs. 16-17.

12. En concreto nos referimos a un investigador. Carlos TÍO SARALEGUI, el cual expresa esta idea en la página 43 de la obra y revista citadas en la Bibliografía final. 
- DNl/NIF

- Escrituras/Contrato de Arrendamiento

- Contribución de los últimos cinco años

- Declaración de la Renta (IRPF) de los últimos cinco años

- Facturas de venta o seguros agrarios de los últimos tres años.

- Un plano o croquis de la finca.

Con tales peticiones no es de extrañar que el éxito de la medida haya sido mínimo. Cuando el agricultor ha conseguido informarse sobre la medida y ha considerado que la cantidad indemnizadora -exigua por cierto- le interesa, encima se encuentra con la exigencia de unos documentos la mayoría de los cuales no posee; entonces desiste totalmente. ¿Cuántos agricultores de hoy realizan contrato de arrendamiento o venden sus pequeñas cantidades con factura?

Seamos sensatos, sólo cuentan con facturas, seguros, contratos de arrendamiento, etc. en regla, aquellas empresas que generalmente son rentables. Sí ya son rentables, difícilmente se van a acoger a estas medidas que les instigan a dejar la actividad agraria. Estas medidas van dirigidas a aquellos agricultores medianos y pequeños a quienes sí les interesa abandonar la actividad porque no les es demasiado rentable. Si estos últimos agricultores sabemos que no poseen generalmente ni facturas, ni seguros, ni contratos, ¿para qué exigírselos? ¿quizás para aseguraros de qué no se van a acoger a las medidas?

Si los nuevos Decretos Nacionales no flexibilizan la exigencia de documentos, será difícil que a las nuevas medidas se puedan acoger un número de agricultores significativo.

\section{BIBLIOGRAFÍA}

CANO GARCÍA, G.: La comarca de Baza, Valencia, Dept. de Geografía. 1974, 523 págs.

COMISIÓN EUROPEA (1991, a) "Documento de reflexión de la Comisión sobre evolución y futuro de la PAC". COM (91), 100 final. Bruselas.

COMISIÓN EUROPEA (1991, b) "Propuesta de la Comisión sobre el desarrollo futuro de la Política Agraria Común. COM (91) 258 final. Bruselas.

CRUZ VILLALÓN, Josefina (1992). El futuro de las agriculturas del sur de Europa en "Las agriculturas del sur de Europa y la reforma de la Política Agrícolas Común. Universidad Menéndez Pelayo. Valencia.

GARCÍA AZCÁRATE, Tomás (1991). “Se ha agotado la Revolución Verde?” Revista de Estudios Agrosociales, $n^{\circ}$ 156, págs. 85-103. Madrid. Ministerio de Agricultura, Pesca y Alimentación. 
INE (1974, 1979). Censo Agrario de 1972. Madrid.

- Serie B. Cuadernos provinciales. Granada.

- Serie C. Resúmenes Nacionales (por provincias).

. Serie A. Primeras facultades. Granada.

INE (1984 y 1985). Censo Agrario de 1982. Madrid.

- Tomo II. Resultados por CC AA pluriprovinciales. Andalucía.

- Tomo III. Resultados provinciales. Granada.

. Tomo IV. Resultados comarcales y municipales. Granada.

INE (1991). Censo Agrario de 1989. Madrid.

. Tomo II. Resultados por CC AA. Andalucía.

- Tomo III. Resultados provinciales. Granada.

- Tomo IV. Resultados comarcales y municipales. Granada.

INE (1982). Censo de Población de 1981. Población de derecho y de hecho de los municipios españoles. Madrid.

INE (1992). Censo de Población de 1991. Avance de resultados. Madrid.

JUNTA DE ANDALUCÍA (1989). Datos estadísticos de la población andaluza Padrón 1986- Servicio de Estadística de la Secretaría de Economía y Fomento (Consejería de Fomento y Trabajo). Sevilla.

TÍO SARALEGUI, Carlos (1991). La Reforma de la PAC desde la perspectiva de las agriculturas del sur de la CEE. Revista de Estudios Agrosociales $n^{\underline{c}}$ 156, págs. 41-66. Madrid. Ministerio de Agricultura. Pesca y Alimentación. 